\title{
Os princípios do Bem Viver na relação com o protagonismo das mulheres
}

\author{
The principles of Good Living in the relationship with women's protagonism \\ Los principios del Buen Vivir en la relación con el protagonismo de las mujeres
}

\section{Resumo}

Este artigo busca discutir, numa perspectiva teórico-prática, os princípios do Bem Viver na relação com o protagonismo das mulheres do quilombo Arruda. Assim o fazemos, com o interesse na reflexão acerca do Movimento Social das Mulheres quilombolas na comunidade de Arrudas - CE, diante dos preceitos do Bem Viver. Opta-se por enfocar a dimensão política de suas reivindicações e propostas, procurando fazer com que a análise contribua para refletir sobre as políticas públicas em seus próprios termos. Além disso, analisa-se a ação do coletivo e sua autoatribuição como mulheres quilombolas, atendendo a possíveis conexões e desligamentos com outros feminismos, a fim de traçar a lógica da política em face à valorização do papel da mulher. Essa análise permite vislumbrar como as mulheres quilombolas se movem entre essas duas lógicas de ação, mas também incita agendar discussões que dizem respeito antropologicamente à relação entre ontologia e política. Para dar conta desse interesse de pesquisa, adotamos como metodologia revisão de literatura com aportes qualitativos. Por fim, podemos afirmar a relação em torno do movimento social de mulheres e os preceitos do Bem Viver.

Palavras-chave: Bem viver; Movimentos sociais; Valorização; Mulheres quilombolas.

\begin{abstract}
This article seeks to discuss, from a theoretical-practical perspective, the principles of Good Living in relation to the protagonism of women from the Arruda quilombo. We do so, with an interest in reflecting on the Social Movement of Quilombola Women in the community of Arrudas - CE, in light of the precepts of Good Living. The option is to focus on the political dimension of their claims and proposals, seeking to make the analysis contribute to reflecting on public policies in their own terms. Furthermore, the collective action and its self-attribution as quilombola women are analyzed, taking into account possible connections and disconnections with other feminisms, in order to trace the logic of politics in face of the valorization of the role of women. This analysis allows us to glimpse how quilombola women move between these two logics of action, but it also encourages scheduling discussions that are anthropologically related to the relationship between ontology and politics. To account for this research interest, we adopted a literature review with qualitative contributions as a methodology. Finally, we can affirm the relationship between the women's social movement and the precepts of Bem Viver.
\end{abstract}

Keywords: Well living; Social movements; Appreciation; Quilombola women. 


\begin{abstract}
Resumen
Este artículo busca discutir, desde una perspectiva teórico-práctica, los principios del Buen Vivir en relación al protagonismo de las mujeres del quilombo de Arruda. Lo hacemos, con interés en reflexionar sobre el Movimiento Social de Mujeres Quilombolas en la comunidad de Arrudas - CE, a la luz de los preceptos de Bem Viver. La opción es enfocarse en la dimensión política de sus reclamos y propuestas, buscando que el análisis contribuya a reflexionar sobre las políticas públicas en sus propios términos. Además, se analiza la acción colectiva y su autoatribución como mujeres quilombolas, teniendo en cuenta las posibles conexiones y desconexiones con otros feminismos, con el fin de trazar la lógica de la política frente a la valorización del rol de la mujer. Este análisis permite vislumbrar cómo las mujeres quilombolas se mueven entre estas dos lógicas de acción, pero también fomenta la programación de discusiones antropológicamente relacionadas con la relación entre ontología y política. Para dar cuenta de este interés de investigación, adoptamos una revisión de la literatura con contribuciones cualitativas como metodología. Finalmente, podemos afirmar la relación entre el movimiento social de mujeres y los preceptos de Buen Vivir.
\end{abstract}

Palabras clave: Buen vivir; Movimientos sociales; Apreciación; Mujeres quilombolas.

\title{
1. Introdução
}

De início, torna-se necessário estabelecer alguns parâmetros gerais acerca do conceito do Bem Viver enquanto perspectiva de desenvolvimento social: o Bem Viver diz respeito a um projeto de desenvolvimento antagônico à produção subsumida à relação hegemônica e industrial/comercial capital-trabalho que, em termos de atividade econômica no campo, traz uma dupla consequência: exploração predatória dos meios e dos recursos naturais; e exploração das capacidades humanas nas próprias relações de produção no campo. Ou seja, aponta-se aqui para a necessidade de desenvolvimento que mantenha o equilíbrio entre o ser social e a natureza em uma perspectiva de desenvolvimento sustentável e eticamente emancipatória.

Pois bem, com as considerações sobre a diversidade das produções socioeconômicas, a partir de outras perspectivas de organização social para além dos cânones consagrados pelas teorias etnocêntricas, e a centralidade do trabalho humano se intenciona pensar o protagonismo feminino em face de projetos de desenvolvimentos antagônicos ao modelo hegemônico.

O presente artigo objetiva, de modo geral, discutir numa perspectiva teórico-prática os princípios do Bem Viver na relação com o protagonismo feminino das mulheres do quilombo Arruda. Em seu lastro crítico e potencialmente emancipatório, os princípios trazem uma dissociação da versão convencional do desenvolvimento como um todo e, consequentemente, acaba-se desafiando a ideia de progresso linear e contínuo - o continuum da história - bandeira da modernidade ocidental, por meio de uma atitude verdadeiramente decolonial.

Vários aspectos, que se encerram no conhecimento tradicional e nativo dos povos, fazem dessa abordagem inovadora uma opção diferente, por isso uma fonte privilegiada, como já foi visto. Ao mesmo tempo, as contribuições em matéria econômica e em torno da natureza são outra questão de particular relevância.

Em seguida, faz-se necessário compreender as premissas econômicas mais significativas com o objetivo de identificar as chaves que fazem do Bem Viver uma alternativa para o desenvolvimento. Como primeiro ponto, é essencial dizer que a economia não implica um ambiente diferenciado, distante e dominante acima de outros aspectos da vida na sociedade.

Nesse sentido, há uma estreita ligação entre aspectos culturais, políticos, sociais e até espirituais e, como um todo, a economia é um desses campos, definidos com e por sua relação com os outros. Essa deslegitimação da esfera econômica como diretriz da vida social vai contra a ideia de um bem-estar definido apenas em relação à renda econômica ou aos bens materiais. Pelo contrário, o Bem Viver entende que o bem-estar dos seres humanos é um processo e uma tarefa em permanente construção, e que é necessariamente moldado por múltiplas dimensões.

Outra questão importante é a ideia de equilíbrio e harmonia que deve ser estabelecida nas relações, sempre dinâmicas, entre Estado, mercado e sociedade. Embora esse suposto equilíbrio esteja próximo das propostas hegemônicas para o desenvolvimento sustentável, entende-se que ele simultaneamente se distancia, enquanto o ponto de partida é a crítica profunda desses conceitos e suas materializações. Esse raciocínio permite reconsiderar a diversidade como outro elemento-chave, que permite revalorizar e tornar visíveis outras economias, nas quais o papel das mulheres e do trabalho assistencial é 
ressignificado.

Seguir essa linha de argumento não significa extinguir a economia de mercado e mudar-se para uma economia popular, mas, sim, a construção de articulações dinâmicas entre as diversas formas de organização econômica. Neste ponto, devemos dizer que, a exemplo das comunidades que dependem da exportação de seus recursos naturais - em particular recursos extrativistas - o desafio é pensar no desenvolvimento acima da economia extrativista, ou seja, avançar em direção a uma economia que permita otimizar a extração bruta sem causar danos ambientais e sociais (Acosta, 2016).

Nesse contexto, a intervenção, as políticas do Estado e as múltiplas formas organizacionais assumidas pelas comunidades e pelos povos são essenciais. O parâmetro que sustenta esse tipo de retorno do Estado entende que ele deve se projetar como um ator importante na economia, mas, ao mesmo tempo, tem que estar atento às possibilidades de ficar preso nos limites e contradições de uma modernização capitalista, na qual esse retorno é claramente funcional.

É apropriado fazer algumas ressalvas sobre as possibilidades específicas de limitar a expansão do regime de acumulação capitalista na periferia do mundo, uma vez que fazê-lo significaria corroer os fundamentos do atual sistema de dominação. Nesse sentido, uma característica do dinamismo capitalista atual é o reforço dos processos de acumulação primitiva, aqueles que se referem à destruição, à violência, à desapropriação, e que estão intimamente ligados ao extrativismo, particularmente difícil para a região latino-americana e, nesse cenário, para o Brasil e para as comunidades quilombolas no contexto da igualdade de gêneros.

Um ponto de extremo distanciamento ao modelo de desenvolvimento hegemônico vem daqueles postulados que abrem a possibilidade de outros tipos de vínculos com a natureza não mediados pelo interesse comercial. Nesse sentido, surgem as inovações políticas necessárias às mulheres quilombolas.

A natureza é estabelecida como um sujeito de direitos, o que implica o reconhecimento de seus próprios valores, independentemente do uso ou utilidade que os seres humanos lhe concedem. Isso não representa nenhuma contradição, pois a natureza é concebida em uma integralidade indissolúvel com o ser humano.

A natureza deixa de representar uma propriedade ou apenas recursos a serem utilizados indefinidamente e insustentavelmente, no entanto, não é uma natureza intocada que não permite culturas ou atividades econômicas, mas direitos que visam defender e manter os sistemas de vida, os conjuntos de vida. Destarte, sua atenção está voltada para os ecossistemas, sobre as coletividades, não sobre os indivíduos (Acosta, 2010, p. 17).

Nesta linha, ressalta-se que não é o bem comum tradicional reduzido ou limitado ao ser humano, mas o bem de todos os seres vivos, incluindo os seres humanos dos quais a complementaridade e o equilíbrio são necessários, não sendo individualmente alcançável (Sólon, 2019).

Nesse viés, a centralidade concedida à natureza junto aos quilombos se replica em uma diferenciação entre a justiça ambiental, voltada para as reparações dos seres humanos por danos ambientais, e a justiça ecológica, que busca garantir a persistência e a sobrevivência das espécies e ecossistemas como redes de vida; o direito à existência dos próprios seres humanos entra nisso.

Há décadas, diversos povos e organizações quilombolas vêm se manifestando com crescente repercussão e visibilidade no espaço público, permitindo mapear não só as demandas dos povos ancestrais, mas também os limites e desafios das sociedades atuais e seus diferentes modelos de governança. Então, exige-se abordar a política interna em seus próprios termos, sem desviar de uma perspectiva ampla que inclui as relações com outros interlocutores.

Nesse viés, é preciso compreender como alimentar as análises para que incluam situações atuais, com perspectiva diacrônica e sem reduzir propostas e categorias quilombolas e indígenas. A partir dessas indagações, o objetivo deste artigo é analisar alguns aspectos das propostas e demandas do Movimento das Mulheres quilombolas pelo viés do Bem Viver, permitindo-se, assim, atualizar novos e antigos problemas do país e da região do Arruda, Araripe - CE. 
Para isso, necessita-se recorrer a noções de política, levando em consideração quais deslocamentos e rupturas o "político" representa como Movimento, bem como quando e como algumas discussões e demandas do coletivo replicam a lógica e as linguagens contenciosas da política. Por fim, busca-se elucidar algumas das questões relacionadas ao coletivo que estão vinculadas às ideias de "ontologia política", categoria oriunda da chamada "virada ontológica" na Antropologia. A lógica de análise, nesse caso, diz respeito aos critérios de ação política - ética, por assim dizer -, mas também à substancialidade ontológica do ser social, ou seja, uma ontologia do ser social no sentido de uma ética materialista e dialética.

Nesse sentido, o trabalho aborda, em primeiro lugar, algumas categorias sobre a política e os trabalhos antropológicos que têm atendido a essas discussões especificamente para o campo do ativismo feminino quilombola no Brasil. Em seguida, analisa-se a composição do grupo, dando atenção específica à dimensão de gênero que o distingue, além de verificar as lutas e demandas que enfrenta, enfocando a ideia de Bem Viver que os aproxima. Destarte, o argumento central é que o movimento das mulheres quilombolas se move constantemente entre a lógica de ação da política, mas também incita a pensar em categorias ontológicas que mapeiam "conexões parciais" entre mundos diferentes.

\section{Metodologia}

A metodologia deste trabalho está pautada em uma revisão de literatura com aportes qualitativos, de modo que o processo de revisão da literatura é uma parte complexa da pesquisa qualitativa, desenvolvendo-se ao longo de toda a investigação, desde a formulação do problema de estudo, passando pela estruturação de um quadro conceitual até o desenvolvimento da discussão ou diálogo teórico (Gil, 2017).

Nesse viés, tal metodologia está focada em oferecer um procedimento inovador que facilite uma revisão da literatura em pesquisas qualitativas com base em um processo analítico metodologicamente estruturado, análise documental e apoiado nas possibilidades técnicas oferecidas.

De acordo com De Pádua (2019), o procedimento metodológico da Análise Bibliográfica serve de suporte para o desenvolvimento do objetivo da pesquisa ao estabelecer os limites de pesquisa do estudo, estimular o desenvolvimento de um arcabouço conceitual por permitir a articulação de indicadores com base em conceitos e facilitar o desenvolvimento da discussão do estudo teórico ou diálogo.

Dessa maneira, pode-se salientar que o resultado final é alinhado pela integração da revisão de literatura do material bibliográfico que sustenta as paráfrases resultantes, sendo esta uma estratégia para posterior resumo de dados e desenvolvimento de categorias analíticas.

\section{Resultados e Discussão}

\subsection{O Bem Viver, as Mulheres e os Movimentos Sociais}

Diante de uma ideia de Bem Viver em diálogo com as diferentes abordagens do protagonismo feminino, pode-se salientar que as correntes feministas dialogaram criticamente e tentaram encontrar alternativas para as mulheres no âmbito das concepções e práticas hegemônicas de desenvolvimento. Dessa forma, busca-se abordar o debate do Bem Viver como uma possível alternativa, podendo estabelecer pontos variados de encontro e fazendo parte das forças de luta que convergiram na definição dessa recente institucionalização.

É importante ressaltar o argumento de que o uso de uma categoria feminina homogênea reduz as mulheres historicamente à condição de gênero, ignorando outros determinantes da identidade, como classe e etnia. A definição de mulheres dos países em desenvolvimento como oprimidas, com status de objeto, faz com que as mulheres do primeiro mundo estejam posicionadas como sujeitos da história e, além disso, possam julgar a partir do universalismo etnocêntrico a família, 
economia, religião, etc., estruturas de outras culturas, tendo como referência os padrões ocidentais, definindo, assim, aqueles que se afastam delas como subdesenvolvidos (Fernandes \& Santos, 2016).

Isso é interpretado pelo autor como uma forma de colonização e apropriação, negando a pluralidade de diferentes grupos de mulheres. Assim como, nessa perspectiva, parece que o único desenvolvimento possível é o do primeiro mundo, tornando invisíveis as experiências de resistência, consideradas marginais, como as experiências das mulheres quilombolas.

Nesse sentido, Urpia et al. (2021) orientam que, quando falamos sobre o mito da fragilidade feminina - que historicamente justifica a proteção paternalista dos homens sobre as mulheres -, de quais mulheres se está referindo?

Cabe dizer, segundo os referidos autores supracitados, que as mulheres quilombolas são parte de um contingente de mulheres, provavelmente maioria, que nunca se reconheceram neste mito, porque nunca foram tratadas como frágeis. As mulheres quilombolas são parte de um contingente de descendentes que trabalharam por séculos como escravizados/as.

Freitas (2017) resume o que poderia ser entendido pelo feminismo pós-colonial como um conjunto de perspectivas feministas que integram a discriminação sexual no quadro mais amplo do sistema de dominação e desigualdade nas sociedades contemporâneas nas quais o racismo e o classismo se destacam. Além disso, também o fazem com o objetivo de decolonizar as correntes eurocêntricas do feminismo, dominantes por décadas e talvez até hoje. Por fim, direcionam seu olhar crítico para a própria diversidade, questionando as formas de discriminação sofridas pelas mulheres dentro das comunidades dos oprimidos e afirmando sua diversidade.

Os movimentos feministas comunitários e populares também poderiam ser considerados decoloniais e surgiram ligados aos movimentos sociais no Brasil e no restante da América Latina, relacionados principalmente a quilombolas e indígenas, no âmbito das lutas contra as reformas neoliberais das últimas duas décadas, que envolveram o fortalecimento do extrativismo e a divisão internacional do trabalho em detrimento de maiorias empobrecidas, principalmente mulheres dos setores popular, indígena, afro-americano e camponês (Passold, 2017).

Este feminismo adquire força especial caracterizado por fazer parte da resistência mais ampla ao neoliberalismo, no processo de buscar a recuperação do Estado em seu papel redistributivo, anti-imperialista e plurinacional. Constitui uma importante contribuição para a institucionalização do Bem Viver, articulando de forma complexa a luta pela descolonização, pela superação do capitalismo e pela construção de uma nova relação com a natureza (Fernandes, 2020).

Nesse mote, depreende-se que os interlocutores não são mais mulheres de classe média, profissionais, mas mulheres negras, indígenas e camponesas que ressignificam o feminismo a partir de seus contextos, experiências, produções culturais do cotidiano e da situação do trabalho, no qual a natureza e a sustentabilidade aparecem como categorias centrais de encontro e também de mobilização.

As contribuições desse feminismo também se traduzem em tensões, visto que movimentos feministas comunitários e populares constituem uma força de luta dentro da rede de atores que buscam imprimir sua visão e interesses na institucionalização do Bem Viver. Nesse sentido, estão pressionando por uma descolonização no sentido feminista, já que, para elas, não é possível a descolonização sem a destituição da sociedade paternalista (Guedes, 2018).

Segundo Da Graça Costa (2018), a liberdade total passa pela descolonização de nossas próprias cabeças e nossos próprios corpos. Na verdade, o que está em questão aqui é a contribuição que o feminismo faz aos processos de descolonização ao pensar na natureza cumulativa das desigualdades; assim, ser uma mulher branca profissional não é o mesmo que uma mulher quilombola. Isso nos leva a pensar não apenas sobre as desigualdades e dominações que ocorrem entre diferentes comunidades e culturas, mas também dentro delas.

Nesse ponto, observa-se que a desigualdade na diferença consiste em interrogar sua própria identidade étnico-racial, a fim de denunciar a discriminação sofrida pelas mulheres dentro de suas comunidades supostamente homogêneas. Outra contribuição igualmente importante (do feminismo) reside em mostrar que o tradicional, o ancestral, não é estático, mas 
dinâmico e muda de acordo com sua própria lógica, seu ritmo e tempo, sem se tornar dependente da pregação liberal eurocêntrica.

Diferentes autores concordam que as comunidades quilombolas devem enfrentar os reais problemas de desigualdade e violência de gênero além do discurso ou proposta que, em certa medida, enfatiza os aspectos positivos de sua cultura e sua relação com a natureza (Ferreira, 2020; Durand, 2020; Dos Santos Muniz, 2019).

Cabe dizer que o questionamento mais difundido desses movimentos feministas às concepções de Bem Viver é sobre a complementaridade, que constitui a relação de gênero da visão de mundo quilombola e que alude a um binarismo particular entre homens e mulheres. É por essa razão que se argumenta, não a favor da necessidade de descartar essa noção, mas de tornála eficaz no cotidiano, construindo um maior papel público para as mulheres e para as organizações feministas, eliminando as hierarquias que estão escondidas por trás da complementaridade (Da Silva, 2019).

Contudo, em vez disso, a referida autora propõe outra maneira de olhar para as relações entre mulheres e homens, ou seja, entendendo que a complementaridade heterossexual da família é a naturalização da opressão, da discriminação, da exploração e dominação das mulheres e, ao contrário disso, propõe substituir a noção de casal por um parceiro político e o da família por uma comunidade. A comunidade é outra forma de entender a sociedade, as práticas culturais existentes, os ritos religiosos, os pressupostos políticos essenciais, não hierárquicos e autônomos umas das outras.

\subsection{O Bem Viver, o papel das mulheres quilombolas e os aspectos econômicos}

De modo que o Bem viver, segundo Acosta (2016), não pode prescindir de abordar a visão do campo econômico, é preciso que este seja pensado à luz das confluências entre os postulados do Bem Viver e dos movimentos feministas. Nessa seara, urge a definição de políticas públicas e marcos regulatórios em termos de economia social e solidária, trabalho, produção e soberania financeira.

Ressalta-se que o Bem Viver constitui um paradigma alternativo às concepções atuais de desenvolvimento, nas quais a visão feminista da economia encontra aceitação. As feministas têm participado de disputas no campo da economia mobilizadas pelas condições de invisibilidade do trabalho feminino e pela concentração das mulheres em tarefas reprodutivas e não remuneradas (Sólon, 2019).

A principal premissa do paradigma econômico, para Acosta (2016), não é pautada pela lógica da acumulação e da reprodução ampliada do capital, mas pela afirmação de uma lógica de sustentabilidade e reprodução ampliada da vida. Dessa forma, a vida e o trabalho são eixos da economia sob os princípios da solidariedade, da reciprocidade, da complementaridade e da cooperação, substituindo a centralidade do mercado e da concorrência e do egoísmo como princípios orientadores.

Destarte, alude-se que, ao contrário do pensamento econômico capitalista - que entende que os indivíduos agem independentemente uns dos outros, na busca por maximizar lucros e lucros - o Bem Viver baseia-se no reconhecimento de que os seres humanos fazem parte da natureza, dependem dela e são interdependentes uns dos outros.

\subsection{A Política, o político e a ontologia política}

A política faz com que o que foi ouvido apenas como ruído seja ouvido como discurso (Rancière 1996, p. 45)

Primeiramente, urge mapear algumas discussões sobre a política e o político inspiradas na obra do cientista político Jacques Rancière, conectando-se às linhagens antropológicas que alimentam este trabalho para, então, empreender a análise do Movimento de Mulheres Quilombolas e o Bem Viver. 
De fato, importa ressaltar que a política e o político respondem principalmente aos debates sobre como compreender o poder, o que é hegemonia e como ela opera, questões imanentes ao campo da teoria política e tratadas, entre muitas outras, pelo filósofo francês (Rancière, 1996).

Voltando-se a Foucault, para Rancière a política e o político constituem duas lógicas (de ação) diferentes e, portanto, devemos renunciar aos conceitos que tentam gerar uma passagem entre os dois domínios. Para Rancière (1996), é o que Foucault faz a partir de sua concepção de poder, que estabelece que, como existem relações de poder por toda parte, tudo é político.

Pelo contrário, para o referido filósofo, para uma coisa ser política, deve dar lugar ao encontro da lógica igualitária, o que também está associado ao Bem Viver, de acordo com Acosta (2016). Afirma-se que a política é geralmente denominada pelo conjunto de processos através dos quais se realizam a agregação e consentimento de vários grupos, a organização de poderes, a distribuição de lugares e funções e os sistemas de legitimação dessa distribuição.

Desse modo, a política é, antes de mais nada, uma ordem dos corpos que define as divisões entre os modos de fazer, os modos de ser e os modos de dizer, o que faz com que tais corpos sejam designados nominalmente a tal lugar e a uma tarefa; é uma ordem do visível e do dizível que torna visível uma determinada atividade. Nesse viés do Bem Viver, a Política é a atividade cujo princípio é a igualdade que se transforma em distribuição das partes da comunidade na forma de um vínculo comunitário (Manfrinate \& Sato, 2012).

De acordo com Da Graça Costa (2018), seja em comunidades quilombolas ou em outros coletivos, a política dentro de uma noção de Bem Viver perfaz uma parte substancial dos processos de construção da hegemonia cultural que, nesse viés de movimentos femininos, consiste em exercer a liderança moral e intelectual, procurando acolher a maior parte das reivindicações que se formulam.

Nesse sentido, destacam que esses processos não buscam tanto construir consensos sobre modos de ser, fazer e dizer, mas, sobretudo, possibilitar linguagens a partir das quais se resolverão divergências sobre a distribuição das partes. Linguagens coletivas, nesse sentido, são importantes porque operam formalizando certas conexões e desconexões com respeito à coletividade, desenhando pontes que estabelecem quem e como se pode transitar pelos espaços sociais (DOS SANTOS, 2016).

Freitas (2017) tem proposto que, para entender a política para os quilombolas, em seus próprios termos, são necessárias ferramentas e categorias que vão além das categorias modernas e/ou (euro) ocidentais. Ou seja, análises que incorporam como reivindicações demandas que se articulam com a lógica da política, mas que também traçam os "excessos", aquilo que a transborda.

Consoante a isso, as mulheres quilombolas, que são ancestrais habitantes deste território, continuam caminhando, fortalecendo sua identidade e resgatando suas vozes que nenhuma outra voz pode representar. É inevitável reconhecer que o lugar de enunciação de onde essas mulheres falam está entrelaçado pela condição de gênero e etnia, enfatizando que nenhuma outra voz pode representá-las.

Em muitas oportunidades, as demandas e propostas devem ser materializadas em histórias de mulheres que, além de torná-las visíveis, também procuram inscrever a violência e a invisibilidade como mulheres quilombolas. Isso, em parte, permite que elas se articulem com outros grupos e referências relacionadas às lutas pela igualdade de gênero, conectando a posição de subordinação em que as mulheres se encontram (Ferreira, 2020).

Nesse sentido, pode-se dizer que as vozes das mulheres quilombolas aparecem rompendo e questionando a ordem estabelecida, vislumbrando que não existem outros espaços coletivos capacitados onde as mulheres quilombolas podem tornar visíveis suas experiências únicas de subalternidade e invisibilidade dentro e fora do campo dos movimentos feministas.

Segundo Guedes (2018), seguindo tal pensamento, infere-se que a política está operando aqui como uma tensão entre a desigualdade vivida e a igualdade proclamada, aquela linguagem comum que lhes permite se conectar e se aliar com outros 
coletivos feministas enquanto disputam a desigualdade de gênero em um contexto no qual a igualdade continua a ser o horizonte para o qual caminhar.

Como ocorre em outras frentes de luta, essas linguagens dos movimentos sociais feministas e as discussões sobre como abordar certas questões não escapam a certas formações discursivas hegemônicas, mesmo dentro do próprio campo das mulheres quilombolas.

\subsection{Os Movimentos das Mulheres Quilombolas e o (Des)colonialismo}

Em primeiro lugar, seguindo o panorama traçado sobre as mulheres quilombolas e o feminismo na comunidade do Arruda - CE, as mulheres dão conta de seus pertences comunitários e reivindicam direitos coletivos como lideranças políticas, comunitárias e espirituais. Nesse sentido, os movimentos de mulheres quilombolas costumam fazer a diferença de outros feminismos ocidentais devido à sua concepção cultural além da luta pela igualdade de gênero.

Sobretudo, de acordo com Durand (2020), a condição de gênero das mulheres quilombolas costuma ser problematizada pela afirmação de especificidades étnicas, culturais e de classe, por meio das quais reforçam as marcas e experiências históricas que as diferenciam das mulheres e dos homens de outras culturas.

A afirmação e a ênfase nessas características específicas que as diferenciam são entendidas por alguns autores como uma intersecção e essa interseccionalidade permite entender o sistema colonial moderno de gênero e, assim, tornar visível o que está oculto quando essas categorias são conceituadas ou declaradas separadamente (PASSOLD, 2017).

Esse colonialismo, desde então, permeou todas e cada uma das áreas da existência social, constituindo a forma mais efetiva de dominação social material e intersubjetiva. Portanto, "colonialidade" não se refere apenas à classificação racial. É um fenômeno abrangente, pois é um dos eixos do sistema de poder e, como tal, permeia todo o controle do acesso aos gêneros, da autoridade coletiva, do trabalho e da subjetividade/intersubjetividade, bem como a produção de conhecimento desde o próprio interior dessas relações intersubjetivas (Urpia et al., 2021).

No recorte do Bem Viver no contexto das mulheres quilombolas, é preciso verificar quais aspectos do gênero são vistos quando se analisa a colonialidade do poder e isto depende da forma como ela é conceituada. No caso dos movimentos feministas quilombolas, interessa resgatar que, embora sua posição de mulheres quilombolas seja inegável, suas ações não giram apenas em torno das discussões do ativismo feminista, mas também se ramificam em outras denúncias e ações políticodiscursivas.

Parte da diferenciação de outros feminismos ligados à etnia branca e ocidental reside no fato de que, ao se apresentarem como um coletivo, essas mulheres destacam as marcações fenotípicas e/ou racializadas que vivenciam e que estão ligadas a experiências de discriminação e subalternização somadas à sua condição como mulheres, tornando inevitável dimensionar a interseccionalidade mencionada (Dos Santos, 2016).

Cabe considerar, contudo, que esta interseccionalidade não é completamente transparente se não atentarmos para as suas outras reivindicações, visto que embora a colonialidade do poder opere através das relações entre raça/classe/sexualidade/gênero localização geográfica ou território/geração, dentre outros, também necessitamos de alguma atenção analítica em outras dimensões políticas a que nos referimos.

No contexto quilombola, os cidadãos desse coletivo se sentem parte e não donos da terra nos diferentes lugares onde estão, visto que precisam se comunicar espiritualmente com ela. É por isso que se comprometem uns com os outros e com seus ancestrais em diferentes lugares. O compromisso com a espiritualidade afro-brasileira é também um compromisso político que deve poder se manifestar nas diversas partes. Por tal motivo, ressalta-se a necessidade de que os espaços cerimoniais sejam respeitados, que sejam reconhecidos como espaços de expressão da espiritualidade, embora estejam longe do lugar de seus ancestrais (Fernandes \& Santos, 2016). 
Assim, estão surgindo discursos e práticas que trazem à existência o debate e a proposta das relações que não são as mesmas que existem a partir da ontologia naturalista hegemônica. Ou seja, não são apenas os significados do território que estão em conflito, mas também as formas de se relacionar com ele.

Há algumas décadas, o feminismo brasileiro e latino-americano vem desenvolvendo um pensamento crítico e uma política que tenta levar em conta as desigualdades de raça e classe em que vive um percentual significativo de mulheres quilombolas. Nesse viés, uma importante abordagem proposta na perspectiva da inclusão foi evidenciada a partir do III Encontro Feminista da América Latina e Caribe realizado no Brasil em 1985, no sentido da necessidade de o feminismo incorporar a problemática da "mulher negra" e suas "representantes" (Dos Santos Muniz, 2019).

Deve-se dizer que, apesar desse aparecimento precoce (embora não tão precoce, levando em consideração a conformação multiétnica e afrodescendente do continente) de conflitos por privilégios étnico-raciais e de classe, a "questão" ocupou poucas páginas em discursos e preocupações do feminismo latino-americano.

Torna-se possível afirmar que, em geral, as tensões em torno da multiplicidade de origens e condições sociais das mulheres na região permaneceram latentes, reaparecendo de vez em quando como um conflito não resolvido, ou graças a algum momento da agenda das Nações Unidas, sem afetar ou modificar substancialmente as visões e práticas dominantes do feminismo regional (Guedes, 2018).

Em geral, segundo o referido autor, a "questão" continua sendo resolvida em termos de "o problema das mulheres negras ou indígenas" a ser incluído na organização dos painéis e reuniões do movimento e em alguns projetos e programas de intervenção compensatória geralmente concebidos e administrados por feministas profissionais da classe média e da supremacia branca no continente.

Apesar disso, de acordo com Durand (2020), não se pode negar que este é o momento em que o debate sobre o multiculturalismo, a explosão de identidades e a reflexão sobre o tema de nossas políticas marcam as preocupações centrais do feminismo em nível global. A menção repetida e tempestiva de "classe, raça, gênero e sexualidade", como final de frase, não é esperada em nenhum texto acadêmico ou discurso de qualquer espécie que se pretenda avançado e politicamente correto; e ninguém admitiria hoje, muito menos no feminismo, que a raça expressa uma condição natural para algum tipo de comportamento esperado ou qualidade específica.

Assim, dentro de um cenário que parece favorecer a atenção ao problema como nunca antes, advém o interesse em desvelar a abordagem dos problemas de raça e classe pelo feminismo quilombola, identificando as condições que historicamente têm impedido um tratamento adequado desses sistemas de opressão na análise e na política do feminismo na região.

Desse modo, faz-se importante ressaltar a constituição histórica particular do feminismo latino-americano em contextos pós-coloniais de longo alcance; o modo como a condição geopolítica desigual tem produzido uma dependência ideológica dos feminismos latino-americanos dos processos e da produção dos discursos do primeiro mundo, definindo assim as ênfases teóricas políticas do movimento; e as dificuldades e obstáculos para a produção de um pensamento e de uma práxis situada que, a partir do reconhecimento dessa marca constitutiva pós-colonial, absorvem o modo como essa condição infalivelmente determina o sujeito do feminismo no quilombo, bem como os objetivos urgentes de sua política (Da Graça Costa, 2018).

Nesse contexto, consoante a autora supracitada, infere-se que se possa pensar em uma reflexão sobre o sujeito e os corpos do feminismo que se instalou como nunca antes, questionando-se inclusive quem ocupa o lugar material dessa reflexão adiada e por que a preocupação se limitou ao corpo sexuado e de gênero sem poder articulá-lo às questões políticas de racialização e empobrecimento que estariam definindo também os corpos que importam em um país como o Brasil. 
Diante da questão dos movimentos sociais e, em particular, no contexto do feminismo, um espaço de visibilidade e recuperação de posições de sujeitos antes não reconhecidas, quais corpos se tornam objeto de representação desse esquecimento e quais são, mais uma vez, apagados e por quê?

Dados os limites da extensão deste estudo, propõe-se concentrar na hipótese de que há uma colonização discursiva da prática acadêmica do feminismo ocidental sobre as mulheres do terceiro mundo e suas lutas, que é preciso desconstruir e desmontar. Para examinar essa cena, a partir do contexto brasileiro, faz-se necessário abordar uma questão que parece altamente eficaz para os fins dessa crítica, ou seja, a denúncia da maneira como a razão pós-colonial (sustentada pelos projetos de nação e cidadania das elites dominantes e intelectuais pós-coloniais) criptografa os grupos como o das mulheres quilombolas, exigindo-os e excluindo-os ao mesmo tempo. Aqui, ressalta-se o feminismo não circunscrito ao universalismo abstrato ocidentocêntrico, enquanto categoria em articulação com os modos e constitutividades específicas do ser em suas demandas, como a questão de classe e raça.

\subsubsection{A Colonização Discursiva}

Por colonização discursiva, entende-se aquela prática acadêmica do feminismo ocidental sobre as mulheres do terceiro mundo que repercute em suas vidas e lutas. O conceito foi proposto em 1986, impelindo uma revisão crítica da obra teórica do feminismo ocidental, suas metodologias eurocêntricas, universalizando falsamente e atendendo a seus próprios interesses; ou seja, um enredo extremamente atual ao se pensar no contexto das mulheres quilombolas (Ferreira, 2020).

Qualquer discussão sobre a construção intelectual e política dos "feminismos do terceiro mundo" deve lidar com dois projetos simultâneos: a crítica interna aos feminismos hegemônicos do "Ocidente" e a formulação de interesses e estratégias feministas com base na autonomia, geografia, história e cultura.

Nesse viés, parece imperativo pensar o feminismo quilombola em sua multiplicidade de discursos, propostas e práticas majoritárias e minoritárias, procurando fazer uma crítica a partir de uma posição geopolítica externa aos feminismos hegemônicos do Ocidente, a fim de articulá-la com os interesses histórico-políticos no sentido de produzir uma crítica, agora interna, dos feminismos com vocação de poder no contexto dos quilombos brasileiros, a exemplo do Quilombo de Arrudas.

Em primeiro lugar, há que se lembrar a origem predominantemente burguesa, branca, urbana e heteronormativa do feminismo latino-americano. Afirmar essa origem não é um fato menor, porque já está amplamente documentado o modo como as classes dominantes e intelectuais, dentro dos quais podemos situar as feministas, foram influenciadas pelo programa político e ideológico do Norte da Europa (Guedes, 2018).

Nesta linha de argumentação e a título de exemplo, é possível se explorar, na contemporaneidade, as conexões entre os projetos de democratização aos quais o feminismo da região atribuía, principalmente no final dos anos 80 , as novas diretrizes da política imperialista neoliberal para os países da América Latina, a exemplo do Brasil.

Importa salientar, também, a evolução dos debates fundamentais dentro da academia e do movimento feminista, bem como nos problemas abordados pelas pesquisas e programas de estudo acadêmico sobre gênero e sexualidade oferecidos nos últimos anos nas Universidades (Fernandes, 2020).

Ao que parece, consoante o referido autor supracitado, de acordo com as investigações realizadas no campo do gênero, há um alto índice de investigações direcionadas ao campo da identidade que se limitam à mera descrição incapaz de investigar como essas identidades são produzidas em contextos específicos de poder. Por outro lado, não se permite estudar a maneira como diferentes categorias de identidade se articulam entre si.

Segundos Dos Santos (2016), esses estudos, seguindo os eixos de preocupação, estratégias e conceituações legitimadas nos países centrais, enfocaram fundamentalmente o estudo das sexualidades dissidentes e da identidade de gênero, sem poder dar conta da interseção irremediável dessas ordens com os de etnia e classe, nem mesmo a forma como essa 
constituição do sujeito da identidade de gênero seria produzida dentro de uma constituição específica dos Estados-nação latino-americanos em contextos de herança colonial e de colonização discursiva.

Neste sentido, é válido inferir que, sob a influência de alguns feminismos e políticas de identidade, o reconhecimento da heterogeneidade, particularidade e diversidade tem ganhado cada vez mais espaço, porém, na prática acadêmica, política e desenvolvimentista, esse reconhecimento tende a ficar no formal e descritivo. Surgem algumas questões como articular analiticamente gênero, raça, etnia, classe social para explicar a desigualdade social que permeia e impede qualquer processo de desenvolvimento em nossos países, para além da mera descrição.

Em consonância, em se tratando da temática das mulheres quilombolas, não se pode aceitar o desenvolvimento de uma reflexão sobre a identidade e sobre os corpos do feminismo a partir de marcos conceituais importados, sem mediação. Destarte, prescinde-se reapropriar esse corpo (muitas vezes abstraído da questão de gênero) aterrissando na materialidade dos corpos racializados, empobrecidos, folclorizados, colonizados de mulheres quilombolas.

\section{Considerações Finais}

O Bem Viver faz parte de uma iniciativa latino-americana enraizada no conhecimento das comunidades quilombolas e em sua história de resistência. É uma alternativa na construção permanente, que envolve um trabalho árduo e criativo em seus mecanismos de manutenção da ancestralidade e da culturalidade.

Trata-se de uma alternativa à abordagem hegemônica do desenvolvimento, cujo principal valor reside no conhecimento e nas práticas contra-hegemônicas anteriormente marginalizadas, que ainda precisam se materializar em um processo de institucionalização nos textos constitucionais do Brasil.

A recuperação das visões de mundo afro-americanas e suas concepções alternativas de natureza, o reconhecimento da interdependência de todos os seres vivos no planeta, a centralidade da vida e do trabalho, a avaliação positiva da diversidade produtiva e reprodutiva da vida, a visibilidade de diferentes protagonistas nos processos econômicos, o questionamento do mercado como esfera central da economia e o importante lugar ocupado pela economia assistencial constituem talvez a fonte de vitalidade privilegiada desse paradigma, no qual claramente o papel ocupado pelas mulheres está sendo revisto.

Por essa razão, os movimentos feministas encontraram um lugar no Bem Viver e tornaram-se uma força concorrente dentro da rede de atores que buscam imprimir sua visão e interesses nos processos sociais em andamento. Dessa forma, principalmente as feministas quilombolas, comunitárias e populares estão pressionando por uma decolonização no sentido feminista.

Como afirmamos no início, entende-se que as possibilidades de renovação e transformação das ciências sociais são uma correlação de sua jornada simultânea com as experiências de resistência de nosso país. Para isso, é essencial revelar-se contra a marca androcêntrica, eurocêntrica e etnocêntrica na construção de um conhecimento científico renovado que simultaneamente apoie os processos decolonizadores e despatriarcalizadores.

A constatação dessa ausência dos corpos afro-americanos, nesta reflexão sobre a temática do feminismo, bem como a necessidade de ampliar seus limites, é preocupante e, ao mesmo tempo, sintomática de como é a produção de conhecimento ainda nesta fase de descentralização do sujeito universal do feminismo, que ainda contém a centralidade eurocêntrica, universalista e, seguidas vezes, não pode fugir dessa colonização histórica por mais que a critique.

Tomando esse exemplo paradigmático, propõe-se pensar sobre a maneira como as agendas de debate e os temas relevantes da pesquisa feminista na região não estão apenas sendo aprisionados (colonizados) pelos quadros conceituais e analíticos dos feminismos do norte, mas também exercendo um papel extremamente produtivo na universalização de tais estruturas interpretativas e na produção contemporânea do sujeito colonial quilombola.

Nessa seara de pensamento, o que se procurou analisar neste estudo reside em se ainda há, de fato, uma colonização 
discursiva das mulheres quilombolas e de suas lutas. Assim, infere-se que os feminismos hegemônicos em ambos os lados do Atlântico tenham contribuído para o projeto colonial de criptografar a "mulher do terceiro mundo". Criptografia que ocorre entre sua expulsão histórica das narrativas da formação do ideal da nação branca ocidental e a necessidade de sua existência como o (verdadeiro) outro.

Nesse sentido, seria parte de uma violência epistêmica à qual as mulheres de minorias quilombolas estão duplamente presas pela colonização discursiva do feminismo ocidental que constrói o "Outro" monolítico no Brasil e na América Latina.

Em outros termos, dentro dessa construção, não há acesso possível a uma verdade revelada da experiência de subordinação. Desse modo, o subordinado não pode dizer nada, pois sua voz continua ofuscada pelos discursos dominantes, ou seja, repetindo a experiência de uns colonizados por outros e muito parece que a esperança de acessar esse ponto de vista privilegiado nada mais é do que utópico.

Destarte, sobre a ligação do Bem Viver com os movimentos feministas quilombolas, depreende-se a urgência e a necessidade de as políticas públicas se preocuparem com a situação dos povos quilombolas e, consequentemente, que esse encontro faça com que cada cidadão revise suas próprias crenças sobre sua participação nessa realidade.

Assim, se o privilégio epistêmico não permite acesso irrestrito a nenhuma verdade sobre a mulher no contexto das comunidades quilombolas. No final, volta-se ao início, ou seja, não há ilusão de discurso que oriente e possa absolver da questão (ética): Como podem as feministas em melhores condições do Norte e do Sul assumir uma responsabilidade histórica com a transformação na vida das mulheres e no planeta? Como garantir que os movimentos feministas não acabem sendo cúmplices dos interesses (neo) coloniais de produção material e simbólica de sujeitos para sua exploração e dominação?

A questão não está fora da sociedade, mas, sim, dentro dela. Nesse sentido, compreende-se a relevância da luta das mulheres quilombolas, alcançando movimentos transfronteiriços contra a globalização do capital, o racismo de corpos e a imposição de limitações às mulheres. Nesse mote, os movimentos quilombolas oferecem a articulação de uma luta antipatriarcal, anticapitalista e antirracista.

\section{Referências}

Acosta, A. (2016). O Bem Viver: uma oportunidade para imaginar outros mundos. Tradução de Tadeu Breda. Autonomia Literária/Elefante.

Acosta, A.; \& Brand, U. (2018). Pós-extrativismo e decrescimento: saídas do labirinto capitalista. Elefante.

Da Graça Costa, M. (2018). Agroecologia, (eco)feminismos e Bem-viver: emergências descoloniais no movimento ambientalista brasileiro. In: Anais eletrônicos, Seminário Internacional Fazendo Gênero, Florianópolis. http://www.en.wwc2017.eventos.dype.com.br/resources/anais/1500257660_AR QUIVO_Agroecologia,ecofeminismosebem-viver-emergenciasdescoloniaisnomovimentoambientalistabrasileiro.pdf.

Da Silva, S. A. (2019). O protagonismo das mulheres quilombolas na luta por direitos em comunidades do Estado de São Paulo (1988-2018). Tese de Doutorado, Pontifícia Universidade Católica de São Paulo, São Srasil. https://tede2.pucsp.br/bitstream/handle/22324/2/Silvane\%20Aparecida\%20da\%20Silva.pdf.

De Pádua, E. M. M. (2019). Metodologia da pesquisa: abordagem teórico-prática. Papirus Editora.

Dos Santos Muniz, I. N. (2019). Atuação das mulheres negras e quilombolas na luta pela terra no Brasil. Emblemas, 16, (1), 102-106. https://www.revistas.ufg.br/emblemas/article/view/56632.

Dos Santos, R. W. (2016). As Mulheres Quilombolas e a Economia Solidária numa Perspectiva de Cultura na Sociedade Ocidental. Revista Fatec De Tecnologia E Ciências, 1, (1), 4-21. https://fatecba.edu.br/revista-eletronica/index.php/rftc/article/view/17.

Durand, M. K.; \& Heidemann, I. T. S. B. (2020). Mulheres Quilombolas e o Itinerário de Pesquisa de Paulo Freire. Texto \& Contexto-Enfermagem, v. 29. https://doi.org/10.1590/1980-265X-TCE-2018-0270.

Fernandes, S. L.; Galindo, D. C. G.; \& Valencia, L. P. (2020). Identidade quilombola: atuações no cotidiano de mulheres quilombolas no agreste de alagoas. Psicologia em Estudo, 25, 1-15. https://doi.org/10.4025/psicolestud.v25i0.45031.

Fernandes, S. L.; \& Santos, A. O. (2020). Itinerários terapêuticos de mulheres quilombolas do agreste alagoano, Brasil. Interfaces Brasil/Canadá, 16, (2), 127143.

Ferreira, M. R. D. S.; Eiterer, C. L.; \& Miranda, S. A. (2020). Raça e gênero na construção de trajetórias de mulheres quilombolas. Revista Estudos Feministas, 28, (3), 1-13. https://doi.org/10.1590/1806-9584-2020v28n363121. 
Research, Society and Development, v. 11, n. 1, e52311125508, 2022

(CC BY 4.0) | ISSN 2525-3409 | DOI: http://dx.doi.org/10.33448/rsd-v11i1.25508

Freitas, T. L. (2018). Questões de gênero e raça nos quilombos: o caso das mulheres quilombolas de Mostardas/RS. In: Anais eletrônicos do VII Seminário Corpo, Gênero e Sexualidade, do III Seminário Internacional Corpo, Gênero e Sexualidade e do III Luso-Brasileiro Educação em Sexualidade, Gênero, Saúde e Sustentabilidade. Rio Grande: Ed. da FURG.

Gil, A. C. (2017). Como elaborar projetos de pesquisa. (6a.ed.), Atlas.

Guedes, A. C. B. (2018). Mulheres quilombolas e uso de plantas medicinais: práticas de cura em Santa Rita de Barreira/PA. Dissertação de Mestrado, Universidade Federal do Pará, Belém-PA, Brasil. http://repositorio.ufpa.br/jspui/bitstream/2011/10283/1/Dissertacao_MulheresQuilombolaUso.pdf.

Hooks, B. (2013). Ensinando a transgredir: a educação como prática da liberdade. Editora Martins Fontes.

Manfrinate, R.; \& Sato, M. (2012). A caminhada das mulheres quilombolas de mata cavalo delineando seu território por entre as trilhas da educação ambiental, Rev. eletrônica Mestr. Educ. Ambient, 28, (1), 48-61. http://repositorio.furg.br/handle/1/3799.

Nascimento, M. B. (2018) [1985]. O conceito de quilombo e a resistência cultural negra. 1985. In: Beatriz Nascimento, Quilombola e Intelectual: Possibilidades nos dias da destruição. Maria Beatriz Nascimento. Diáspora Africana: Editora filhos da África.

Passold, S. B. C. (2017). Desapocadas: concepções de beleza e conhecimentos tradicionais de mulheres quilombolas do Puris-MG. Dissertação de Mestrado, Universidade de Brasília, Brasília, DF, Brasil. https://repositorio.unb.br/handle/10482/31151.

Rancière, J. (1996). O Desentendimento: Filosofia e Política. Editora 34.

Ribeiro, D. (2016). Feminismo negro para um novo marco civilizatório. SUR 24, 13, 24, 99-104. https://sur.conectas.org/wp-content/uploads/2017/02/9-sur24-por-djamila-ribeiro.pdf.

Solón, P. (2019). Alternativas sistêmicas: Bem Viver, decrescimento, comuns, ecofeminismo, direitos da Mãe Terra e desglobalização. Tradução de João Peres, Elefante.

Urpia, A. M. de O.; Santos, K. B.; \& Carneiro, S. R. de O. (2021). "O imperativo de contar": uma pesquisa-ação com mulheres e crianças quilombolas. Educar em Revista, 37, 1-22. https://doi.org/10.1590/0104-4060.75599. 